\title{
REPLY COMMENT
}

\section{Bird mortality due to the Deepwater Horizon oil spill: Reply to Sackmann \& Becker (2015)}

\author{
J. Christopher Haney ${ }^{1,4, *}$, Harold J. Geiger ${ }^{2}$, Jeffrey W. Short ${ }^{3}$ \\ ${ }^{1}$ Terra Mar Applied Sciences LLC, 123 W. Nye Lane, Suite 129, Carson City, NV 89706, USA \\ ${ }^{2}$ St. Hubert Research Group, 222 Seward, Suite 205, Juneau, AK 99801, USA \\ ${ }^{3}$ JWS Consulting LLC, 19315 Glacier Highway, Juneau, AK 99801, USA \\ ${ }^{4}$ Present address: Defenders of Wildlife, $113017^{\text {th }}$ Street, NW, Washington, DC 20036-4604, USA
}

\begin{abstract}
Sackmann \& Becker (2015; Mar Ecol Prog Ser 534:273-277, this volume) question assumptions we used to estimate bird mortalities from the 2010 Deepwater Horizon blowout in the northern Gulf of Mexico, recommending spill- and Gulf of Mexico-specific data, especially for estimating the probability of shoreline deposition of seabird carcasses killed at sea. The carcass drift and sinking study they recommend provides limited insight regarding shoreline deposition probability, because it fails to account for advection of tagged carcasses out to sea, the effects of tethering carcasses to buoyant floats, the time to abdominal cavity penetration by scavengers, or the very different conditions when the study was conducted in summer 2011 in comparison with the wind and current regime immediately following the blowout in spring 2010. Recognizing such limitations in studies of seabird carcass drift and sinking at sea, we think that the modeling approach we used, which provides parameter estimates primarily as uncertainty distributions rather than focusing on point estimates from single studies, more faithfully represents the state of knowledge supporting such estimates.
\end{abstract}

KEY WORDS: Deepwater Horizon - Avian mortality · Exposure probability · Carcass sampling · Oil spill $\cdot$ Gulf of Mexico $\cdot$ Christmas Bird Count $\cdot$ Marine birds

\section{Introduction}

We thank Sackmann \& Becker (2015, this volume) for comments on our recent articles estimating seabird mortalities caused by the 2010 Deepwater Horizon blowout in the northern Gulf of Mexico (GoM; Haney et al. 2014a,b) and consequent opportunity to clarify the bases for our estimates. We agree that spill- and GoM-specific data could reduce model uncertainty. We find data from their carcass drift study helpful, although careful inspection actually corroborates our values of shoreline deposition probability. We also explain our assumptions and methods for spatial extent of the spill, the probability of oiling and mortality after exposure, and our analysis of the National Audubon Society Christmas Bird Count data.

${ }^{*}$ Corresponding author: chaney@defenders.org

\section{Shoreline deposition probability for birds killed offshore}

Sackmann \& Becker (2015) estimate a shoreline carcass deposition probability lower than ours by a factor of 18, based on a bird carcass drift and sinking study conducted by the Natural Resource Damage Assessment (NRDA) Trustees and BP during July and August 2011 (13 to 14 months after the Deepwater Horizon blowout). Some results from the NRDA/BP study were released publicly on 27 August 2014, when our second article was in the final stages of production, and hence too late for us to address. However, after carefully evaluating the NRDA/BP data, we find that we would not have altered our estimates or analysis, for 4 important reasons.

() The authors 2015. Open Access under Creative Commons by Attribution Licence. Use, distribution and reproduction are unrestricted. Authors and original publication must be credited. 
(1) Sackmann \& Becker's estimate of $0.054 \mathrm{~d}^{-1}$ for the instantaneous carcass sinking rate is based on a difference between shoreline retrieval of radiotransmitter tags attached to bird carcasses and those attached to dummies (plastic containers of similar size and density). While the rationale given in the NRDA/BP study plan for this comparison is to control for transmitter failure (Ford \& Varela 2011), this approach does not account for tags on both carcasses and dummies that were irretrievably advected out to sea. Clearly, carcasses advected far out to sea are unlikely to reach the shorelines that were monitored for carcass deposition, and these carcasses should be considered in estimates of shoreline deposition probability. We implicitly accounted for these advective losses in our study through use of average shoreward wind velocities, because the average velocity shoreward is decreased by the magnitude and duration of offshore winds. Accounting for these advection losses doubles Sackmann \& Becker's estimate of instantaneous carcass loss rate to $0.112 \mathrm{~d}^{-1}(=-[1 / 8] \ln [81 / 199]$, assuming an average time at sea of $8 \mathrm{~d}$ ).

(2) According to 'Collection Comments' associated with retrieved carcass tags in the data spreadsheet (GSD 2014) cited by Sackmann \& Becker (2015), 33 of 81 'carcasses' retrieved from shorelines were actually remnants of skin, feathers and leg fragments still attached to positively-buoyant radio tags. Given the emphasis on prompt retrieval of carcasses once deposited on shorelines in the NRDA/BP study plan (Ford \& Varela 2011), most damage inflicted on these carcasses likely occurred at sea. Carcasses rapidly lose buoyancy once the abdominal cavity is penetrated (Wiese 2003), making this the key factor determining carcass sinking rate at sea. The time from carcass deployment at sea to initial penetration of the abdominal cavity by scavengers cannot be determined from data produced by the NRDA/BP study, but quite likely occurred within the first day or so, such that carcass remnants still attached to the radio tag flotation would otherwise have sunk soon thereafter. Conversely, based on the 4 carcass 'Collection Condition' records that indicate deposition of an intact carcass on the shoreline (the rest were either noted as 'heavily scavenged' or 'mummified/skeletal'), an estimate for instantaneous carcass loss rate at sea could be computed as $0.488 \mathrm{~d}^{-1}(=-[1 / 8] \ln [4 / 199])$. This result agrees with an estimate of instantaneous carcass loss $\left(1.0 \mathrm{~d}^{-1}\right)$ that we used to guide us in developing our probability distribution to within a factor of $\sim 2$. Although the $0.488 \mathrm{~d}^{-1}$ value leads to a shoreline deposition probability $(r)$ of 0.159 , greater than the upper bound of the $95 \%$ uncertainty inter- val we gave for $r$ of 0.093 (in Table 1 of Haney et al. 2014a), the difference may well be the result of the differing wind and current regimes present in summer of 2011 when the NRDA/BP study was conducted in comparison with winds and currents during spring and summer 2010 when the Deepwater Horizon blowout occurred.

(3) The apparent agreement of Sackmann \& Becker's (2015) carcass sinking rate estimate of $0.054 \mathrm{~d}^{-1}$ with estimates of bird carcass sinking rates from Ford et al. (1996) in the much cooler Gulf of Alaska is actually strong evidence that Sackmann \& Becker's (2015) estimate is too low. As we noted in our supplemental material in Haney et al. (2014b), biological degradation rates in the warmer Gulf of Mexico are expected to be faster (see also Nero et al. 2013) by a factor of about 3, compared to waters as cool as the Gulf of Alaska. The Ford et al. (1996) study also involved carcasses tethered to positively buoyant floats, which artificially delayed carcass sinking to some unknown degree.

(4) The NRDA/BP study was conducted $>1$ yr after the Deepwater Horizon incident, when wind and current conditions were substantially different (e.g. Fig. 1). In 2010, response authorities opened floodcontrol gates on the Mississippi River to redirect the discharge and prevent or delay Deepwater Horizon oil from reaching the coastal marshes, an action which would, of course, also impede shoreward transport of carcasses. Hence, while the NRDA/BP study may be 'GoM- and spill-specific' with respect to space, it is not so with respect to time.

In light of these considerations, we do not find compelling justification to alter our findings regarding the probability of shoreline deposition for carcasses killed at sea by the Deepwater Horizon blowout.

\section{Spatial extent of the spill}

Based on the Textural Classifier Neural Network Algorithm (TCNNA) for processing synthetic aperture radar (SAR) data (Garcia-Pineda et al. 2013), Sackmann \& Becker (2015) advocated $10750 \mathrm{~km}^{2}$ as the average daily spatial extent of oil during the Deepwater Horizon blowout (instead of $19000 \mathrm{~km}^{2}$, the value we used). However, SAR data fail to delineate the full extent of an oil slick on the ocean surface if (1) winds are chaotic or fall outside the optimal detection range of 1.5 to $6.0 \mathrm{~m} \mathrm{~s}^{-1}$ (Fingas \& Brown 2014); (2) shadowing in the SAR imagery arises due to the coastline, bathymetry, and currents; or (3) low detection arises due to SAR incident 
Realtime Mesoscale Altimetry 05/20/2010

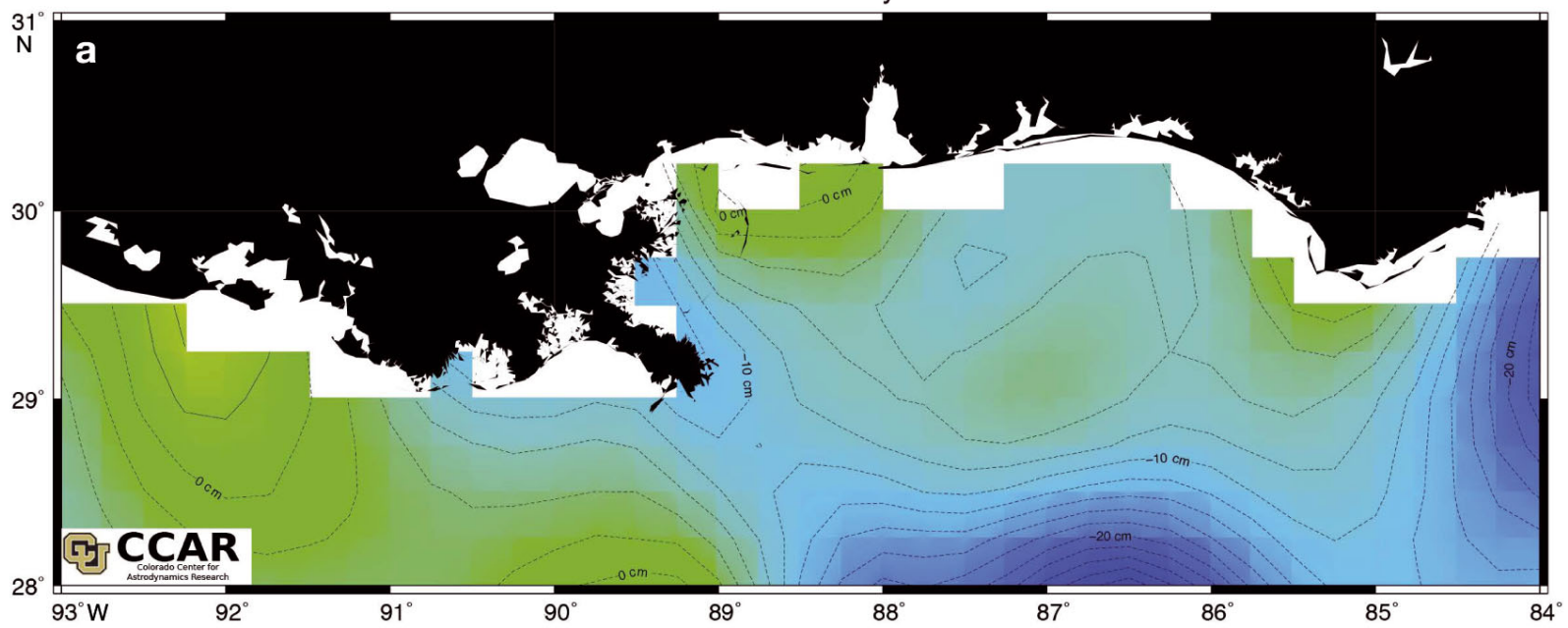

Realtime Mesoscale Altimetry 08/05/2011

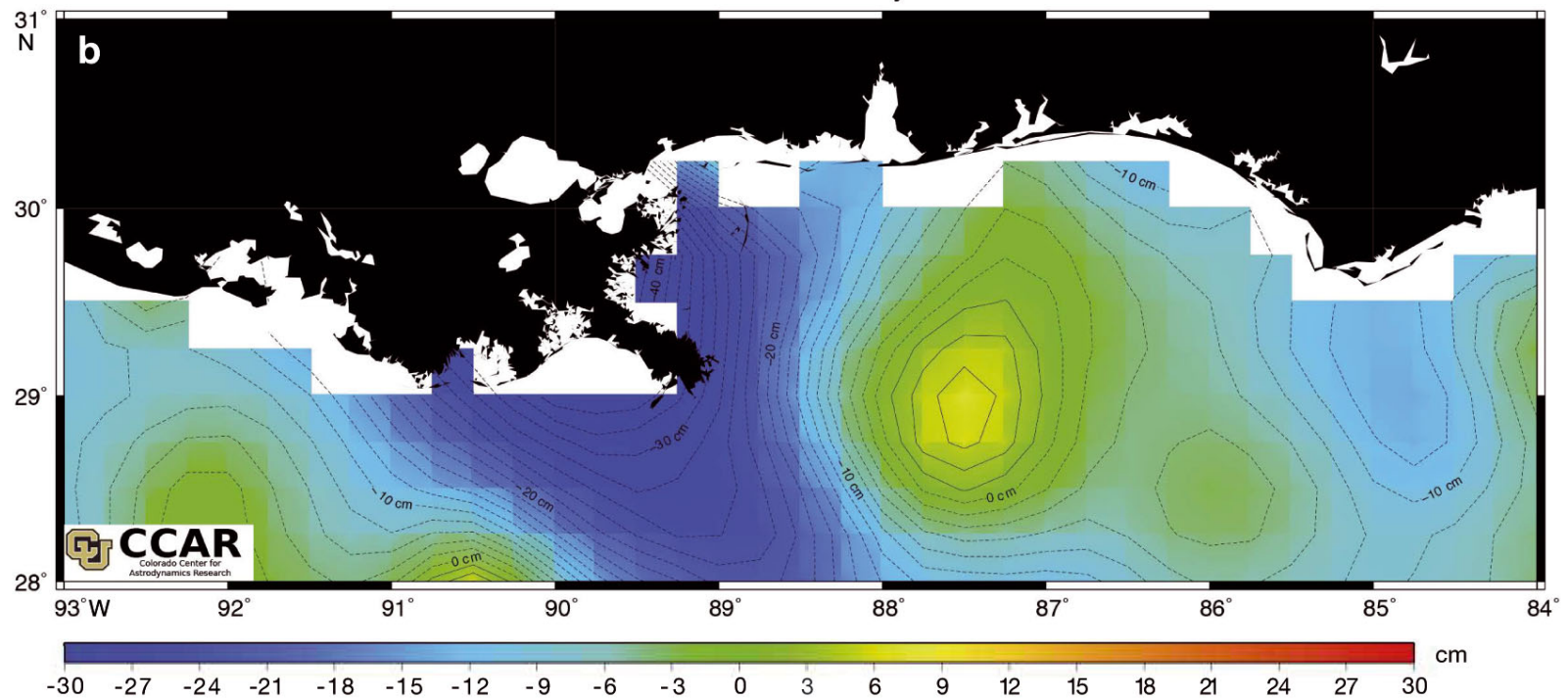

Fig. 1. Contrast in geostrophic currents between (a) 20 May 2010 (during the Deepwater Horizon blowout) and (b) the JulyAugust 2011 bird carcass drift and sinking study cited by Sackmann \& Becker (2015). Each contour line indicates $2 \mathrm{~cm}$ of dynamic sea surface height. Shading - deep blue: cyclonic flow; yellow and orange: anti-cyclonic flow. Approximately 190 of 314 drifters ( $60 \%)$ deployed in the 2011 drift and sinking study were deployed between $87.5^{\circ}$ and $89.3^{\circ} \mathrm{W}$, a region of the northern Gulf of Mexico with strong shoreward flow. In contrast, mesoscale currents were generally weaker, and oriented alongshore or offshore during the Deepwater Horizon blowout (historical altimetry can be customized for any date at: http://eddy.colorado.edu/ccar/ssh/nrt_gom_grid_viewer; accessed 16 June 2015)

angle and beam mode (Supplement in Haney et al. 2014a).

During the Deepwater Horizon blowout, mean daily wind speed exceeded this effective SAR threshold of $6 \mathrm{~m} \mathrm{~s}^{-1}$ on 26 of 103 days (25\% of the active blowout, based on winds measured at NOAA buoy station BURL1, Southwest Pass, LA; www.ndbc.noaa.gov/ station_page.php?station=burl1). In part due to these conditions, we regard a synthesis of satellite imagery and other sources in the Experimental Marine Pollution Surveillance Daily Composites Products to better represent oil extent than the SAR data alone. Nevertheless, for reasons already presented (Supplement in Haney et al. 2014a), we believe even these values likely under-represent the actual exposure risks posed to birds during Deepwater Horizon blowout.

\section{Oiling and mortality}

Sackmann \& Becker (2015) request a more complete explanation of how we arrived at our values for 
proportionate mortality $(M)$. We did not apply an algorithm to data presented in Camphuysen \& Heubeck (2001) to arrive at the values we used, as implied by Sackmann \& Becker's (2015) request. Instead, we selected a probability distribution such that the mean and standard deviation together encompassed values of $M$ that we considered plausible in light of all available information from the literature and the bird carcasses collected following the Deepwater Horizon blowout. With respect to the data in Camphuysen \& Heubeck (2001), the mean and standard deviation of the beta distribution we chose to represent uncertainty in $M$ ensured that $M$ rarely exceeded the median value of the Camphuysen \& Heubeck (2001) data of $61 \%$. While this approach is somewhat subjective, it has the great advantage of implicitly including a wide variety of assumptions about $M$, and doing so transparently. Given large uncertainties in all the parameters, it seemed preferable to model those uncertainties as faithfully as possible, rather than fixating on any one value associated with a confidence interval of dubious validity (e.g. one constructed from the range of parameters for $M$ given in Camphuysen \& Heubeck 2001, which are not independent observations of the same parameter measured under identical conditions).

Furthermore, Sackmann \& Becker (2015, p. 275) assert that '...bird species differ in their sensitivity to degree of oiling (NOAA 1996), ' but the NOAA (1996) document cited does not support this assertion. Instead, the NOAA (1996) guidance indicates that bird guilds have different sensitivities to oil with regard to likelihood of exposure, with alcids or seaducks, for example, being more vulnerable to contact with an oil slick at sea than shorebirds. But once oiled, the NOAA (1996, p. 32 of Chapter 3) guidance is quite clear regarding the most probable outcome, stating: 'Typically, surface slicks are assumed to be lethal to wildlife (mammals, seabirds).' Even a thin sheen compromises plumage integrity (e.g. O'Hara \& Morandin 2010) and hence chances for survival. Self-cleaning prospects for birds contaminated with small specks of oil $(<10 \%$ of plumage) are considered 'rarely successful' or even 'impossible,' with long-term survival prospects scored as 'bleak' or 'none' (Camphuysen 2007). Consequently, any contact with macroscopically evident oil by seabirds is typically assumed to lead to mortality. In this context 'macroscopically evident' refers to visibility to an observer in the immediate vicinity, not necessarily to a satellite that can only detect the more extensive (and thicker) oil slicks. Hence, the intimation that seabirds have varying sensitivities to oiling is not supported by NOAA (1996), nor by other studies. We therefore stand by the assumptions we made regarding the probability of oiling and the proportionate mortality $M$.

\section{Christmas Bird Count}

We share the concerns raised by Sackmann \& Becker (2015) regarding the National Audubon Society Christmas Bird Count data as a basis for detecting changes in the laughing gull population in the GoM. The $\sim 60 \%$ decline in the CBC index we noted from 2009 to 2010 was based on comparison of the ratio of the sum total of laughing gulls sighted during the $\mathrm{CBC}$ and the sum total of party hours from all stations in the 5 US GoM states. This approach of calculating the overall sightings per unit effort (SPUE) is akin to use of catch per unit effort (CPUE) computations as an estimator of fisheries population sizes. The result is 39.8 laughing gull sightings per party hour in 2009 ( $\mathrm{n}=101$ stations) and 16.4 in 2010 ( $\mathrm{n}=98$ stations), a decline of $59 \%$. However, this apparent decline depends on inclusion of the result from the TXHO station in 2009. Without this station, the 2009 SPUE becomes 14.6, which would suggest a negligible change in population from 2009 to 2010. We did not realize the leverage provided by the result from the TXHO, nor did we consider results from years prior to 2009 in our analysis, and we thank Sackmann \& Becker for bringing these points to our attention.

While we concede that the CBC data are not as corroborative of our estimates of bird mortalities caused by the Deepwater Horizon blowout as we had thought, we do not consider the absence of such corroboration as evidence against our mortality estimates. Detecting the $\sim 35 \%$ decline of laughing gulls that we presented in Table 3 of Haney et al. (2014b) is inherently problematic given the high inter-annual variability of the SPUE we computed for this species. Inter-annual changes of the SPUE for the years 2000 to 2008 range from $-26 \%$ to $+64 \%$, which could substantially obscure an actual decline of $\sim 35 \%$.

\section{Discussion}

We agree with Sackmann \& Becker (2015, p. 276) that a '...reliable and credible estimate of seabird mortality after the DHOS [Deepwater Horizon oil spill] requires detailed evaluation of assumptions, modeling methods, and parameter estimates.' However, we think that our use of probability to weight 
various parameter assumptions, producing a distribution of bird mortality estimates is far superior to reliance on a single sample statistic from a single carcass drift study in the same area as the oil spill but from a different year.

In conclusion, we think that our study faithfully reflects the uncertainties associated with estimation of seabirds killed by exposure to oil from the Deepwater Horizon blowout, especially those associated with transport of carcasses that died at sea to the shorelines that were monitored for carcass deposition. We therefore stand by the estimates we reported in Haney et al $(2014 a, b)$.

Acknowledgements. All findings in this Reply Comment reflect those of the authors only; interpretations do not reflect positions that may be held by any organization, entity, or other interest.

\section{LITERATURE CITED}

Camphuysen CJ (2007) Chronic oil pollution in Europe, a status report. Royal Netherlands Institute for Sea Research, Brussels. Available at www.ifaw.org/sites/default/ files/Chronic\%20oil\%20pollution\%20in\%20Europe.pdf (accessed 17 June 2015)

Camphuysen CJ, Heubeck M (2001) Marine oil pollution and beached bird surveys: the development of a sensitive monitoring instrument. Environ Pollut 112:443-461

Fingas M, Brown C (2014) Review of oil spill remote sensing. Mar Pollut Bull 83:9-23

Ford RG, Bonnell ML, Varoujean DH, Page GW and others (1996) Total direct mortality of seabirds from the Exxon Valdez oil spill. Am Fish Soc Symp 18:684-711

Ford RG, Varela V (2011) Using radio telemetry to determine the fates of bird carcasses drifting in the northern

Editorial responsibility: Christine Paetzold,

Oldendorf/Luhe, Germany
Gulf of Mexico (Bird Study \#1D). Available at www. doi.gov/deepwaterhorizon/adminrecord/upload/BIRD_T elemetry_Carcass_Drift_1D_corrected-signature-pagefinal-executed-plan.pdf (accessed 14 July 2015)

Garcia-Pineda O, MacDonald IR, Li X, Jackson CR, Pichel WG (2013) Oil spill mapping and measurement in the Gulf of Mexico with Textural Classifier Neural Network Algorithm (TCNNA). IEEE J Sel Topics Appl Earth Observ Remote Sens 6:2517-2525

GSD (Gulf Science Data) (2014) Data inputs for beached bird assessment data file. http://gulfsciencedata.bp.com/, directory: Birds; subdirectory: Data Inputs for Beached Bird Assessment; filename: BirdsBeachedBirdData_B09v01-01.xlsx (zipped). Last modified August 2014

Haney CJ, Geiger HJ, Short JW (2014a) Bird mortality from the Deepwater Horizon oil spill. I. Exposure probability in the offshore Gulf of Mexico. Mar Ecol Prog Ser 513: 225-237

Haney CJ, Geiger HJ, Short JW (2014b) Bird mortality from the Deepwater Horizon oil spill. II. Carcass sampling and exposure probability in the coastal Gulf of Mexico. Mar Ecol Prog Ser 513:239-252

> Nero RW, Cook M, Coleman AT, Solangi M, Hardy R (2013) Using an ocean model to predict likely drift tracks of sea turtle carcasses in the north central Gulf of Mexico. Endang Species Res 21:191-203

NOAA (National Oceanic and Atmospheric Administration) (1996) Injury assessment: guidance document for Natural Resource Damage Assessment under Oil Pollution Act of 1990 Appendix D. NOAA, Silver Springs, MD. www. darrp.noaa.gov/library/pdf/iad.pdf (accessed 13 July 2015)

O'Hara PD, Morandin LA (2010) Effects of sheens associated with offshore oil and gas development on the feather microstructure of pelagic seabirds. Mar Pollut Bull 60: 672-678

Sackmann BS, Becker DS (2015) Bird mortality due to the Deepwater Horizon oil spill: Comment on Haney et al. (2014a,b). Mar Ecol Prog Ser 534:273-277

Wiese FK (2003) Sinking rates of dead birds: improving estimates of seabird mortality due to oiling. Mar Ornithol $31: 65-70$

Submitted: July 17, 2015; Accepted: August 7, 2015

Proofs received from author(s): August 17, 2015 